\title{
Detection of Human Papillomavirus in Korean Breast Cancer Patients by Real-Time Polymerase Chain Reaction and Meta-Analysis of Human Papillomavirus and Breast Cancer
}

Jinhyuk Choi · Chungyeul Kim Hye Seung Lee · Yoo Jin Choi Ha Yeon Kim · Jinhwan Lee Hyeyoon Chang · Aeree Kim

Department of Pathology, Korea University Guro Hospital, Seoul, Korea

Received: April 26, 2016

Revised: June 12, 2016

Accepted: July 8, 2016

Corresponding Author Aeree Kim, MD, PhD

Department of Pathology, Korea University Guro Hospital, 148 Gurodong-ro, Guro-gu, Seoul 08308, Korea

Tel: +82-2-2626-1741

Fax: +82-2-2626-1846

E-mail:Ark@korea.ac.kr

\begin{abstract}
Background: Human papillomavirus (HPV) is a well-established oncogenic virus of cervical, anogenital, and oropharyngeal cancer. Various subtypes of HPV have been detected in $0 \%$ to $60 \%$ of breast cancers. The roles of HPV in the carcinogenesis of breast cancer remain controversial. This study was performed to determine the prevalence of HPV-positive breast cancer in Korean patients and to evaluate the possibility of carcinogenic effect of HPV on breast. Methods: Meta-analysis was performed in 22 case-control studies for HPV infection in breast cancer. A total of 123 breast cancers, nine intraductal papillomas and 13 nipple tissues of patients with proven cervical HPV infection were tested by real-time polymerase chain reaction to detect 28 subtypes of HPV. Breast cancers were composed of 106 formalin-fixed and paraffin embedded (FFPE) breast cancer samples and 17 touch imprint cytology samples of breast cancers. Results: The overall odds ratio between breast cancer and HPV infection was 5.43 (95\% confidence interval, 3.24 to 9.12 ) with $1^{2}$ $=34.5 \%$ in meta-analysis of published studies with case-control setting and it was statistically significant. HPV was detected in 22 cases of breast cancers (17.9\%) and two cases of intaductal papillomas (22.2\%). However, these cases had weak positivity. Conclusions: These results failed to serve as significant evidence to support the relationship between HPV and breast cancer. Further study with larger epidemiologic population is merited to determine the relationship between HPV and breast cancer.
\end{abstract}

Key Words: Breast neoplasms; Human papillomavirus; Real-time polymerase chain reaction; Meta-analysis
Human papillomavirus (HPV) is a known oncogenic virus associated with uterine cervical cancer, anogenital cancer, and oropharyngeal cancer. It has been proven that HPV proteins E6 and $\mathrm{E} 7$ can bind to $\mathrm{p} 53$ and retinoblastoma protein in epithelial cells and interact with growth-regulating system in uterine cervix, anus, and oropharynx. ${ }^{1,2}$ Almost all uterine cervical cancers and anal cancers are associated with HPV infection. ${ }^{1} \mathrm{HPV}$-mediated oropharyngeal squamous carcinomas have different disease entity from conventional oropharyngeal squamous carcinomas associated with chemical mutagens. ${ }^{3}$ However, the role of HPV in mammary carcinogenesis still remains controversial because various risk factors such as genetic predisposition, diet, hormonal status, life style, and their interactions are involved complexly in the pathogenesis of breast cancer. ${ }^{4} \mathrm{HPV}$ infection has been reported in $4.4 \%$ to $60 \%$ of breast cancers. ${ }^{5-29}$ Various subtypes of HPV including HPV-11, HPV-16, HPV-18, HPV-33, HPV-58, HPV59, HPV-73, and HPV-82 are candidate subtypes of HPV asso- ciated with breast cancers. On the contrary, some studies could not detect HPV infection in breast cancers. ${ }^{30-33}$ Furthermore, HPV infections have been detected not only in breast cancers, but also in various benign breast lesions such as fibroadenoma and intraductal papilloma. To the best of our knowledge, metaanalysis has not been performed yet to evaluate the relationship between HPV infection and breast cancer in a case-control setting. Therefore, the objective of this study was to perform meta-analysis between HPV infection and breast cancer to determine the prevalence of HPV-positivity in breast cancer, to determine whether any specific HPV subtypes are associated with breast cancer, and to evaluate the possibility of sexual transmission of HPV from genitals to breast. 


\section{MATERIALS AND METHODS}

\section{Meta-analysis}

A systematic literature search was conducted in PubMed (January 1, 1992, to September 30, 2015) with the following keywords: "breast neoplasm" and "human papillomavirus." All potentially relevant studies were reviewed. Studies with casecontrol setting were selected. Analyses were performed using R ver. 3.2.2 (2015-08-14) statistical software.

\section{Tumor samples}

The study was performed with 123 breast cancers and nine intraductal papillomas. These patients received surgeries at Korea University Guro Hospital from January 2007 to January 2015. The study protocol was approved by the Institutional Review Board of Guro Hospital. The 123 breast cancer samples were composed of 106 formalin-fixed and paraffin embedded (FFPE) tissues and 17 touch imprint cytology samples. The patients who received mastectomy and nipple resection were preferentially selected to obtain FFPE nipple tissues. The touch imprint cytology samples were also used to compare FFPE tissues and cytology samples. The nine intraductal papillomas samples were composed of nine FFPE tissues. To define the infection route by detecting HPV in nipple, 13 FFPE nipple tissues of breast cancer patients who had been confirmed with HPV infection in uterine cervix were included in this study. All materials were obtained from the tissue bank of Korea University Guro Hospital. Medical records and pathological reports of patients and histological features of breast cancer enrolled in this study were reviewed.

\section{DNA isolation}

Two or three 10- $\mu \mathrm{m}$ sections were taken from FFPE tissues. Deparaffinization of these sections was sufficiently done by xylene and ethanol treatment for 5 minutes alternately for three times. DNA was extracted using QIAamp DNA Mini Kit (Qiagen $\mathrm{GmbH}$, Hilden, Germany) according to the manufacturer's instruction. The concentration of extracted DNA was measured on Nanodrop 2000 (Thermo Fisher Scientific, Wilmington, DE, USA). The quality of DNA was determined by evaluating A260/ A280 ratio. DNA isolation from touch imprint sample from fresh breast cancer was also performed with QIAamp DNA Mini Kit according to the manufacturer's instruction.

Table 1. The published studies of HPV and breast cancer in case-control setting

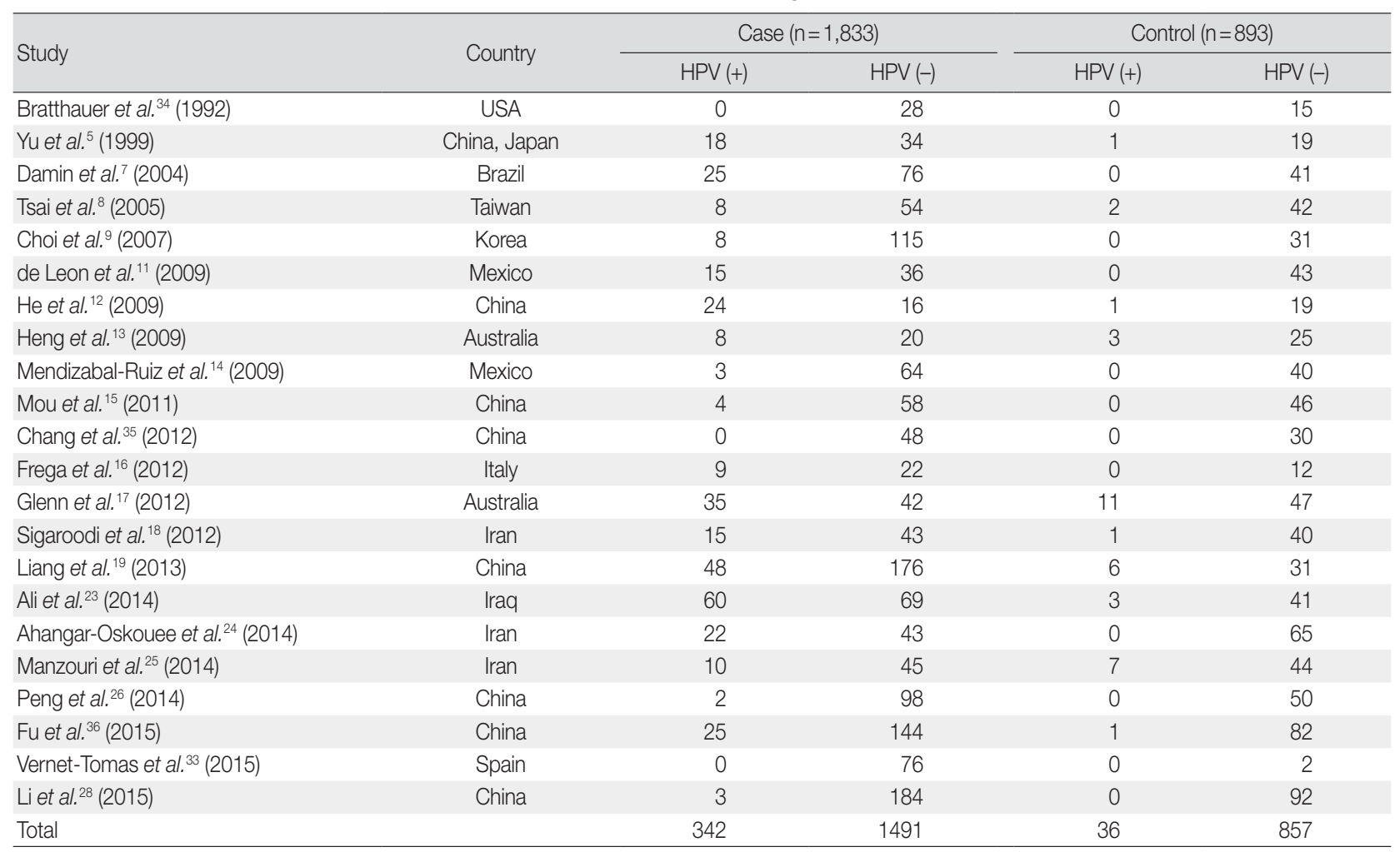

HPV, human papillomavirus. 


\section{Real-time polymerase chain reaction}

Extracted DNA samples were subject to real-time polymerase chain reaction (PCR) with gene specific primers provided with Anyplex II HPV 28 Detection System (Seegene, Seoul, Korea) using CFX96 Real-Time PCR (Bio-Rad, Hercules, CA, USA). Melting curves were analyzed using the exclusive analysis program provided with the Anyplex II HPV 28 Detection System. This system is able to detect 28 subtypes of HPV, including all subtypes reported in the literatures, such as HPV-11, HPV-16, HPV-18, HPV-33, HPV-58, HPV-59, HPV-73, and HPV-82. Because the Anyplex II HPV 28 Detection System was originally designed for cytological samples swabbed in uterine cervix, verification of Anyplex II HPV 28 Detection System with FFPE tissue of uterine cervical squamous cell carcinoma was performed.

\section{RESULTS}

\section{Meta-analysis}

Twenty-two case-control studies for HPV infection in breast cancer were enrolled in meta-analysis with random effect model. HPV infection was detected in 342 of 1,833 breast cancers and in 36 of 857 benign breast lesions (Table 1). The overall odds ratio between breast cancer and HPV infection was 5.43 (95\% confidence interval, 3.24 to 9.12) with $\mathrm{I}^{2}=34.5 \%$ (Fig. 1). This result was statistically significant.

\section{Clinicopathologic data}

The median age of 123 breast cancer patients was 51.6 years (range, 23 to 79 years). The 123 breast cancers included 103 invasive carcinomas of no special type, five invasive lobular carcinomas, one microinvasive carcinoma, three ductal carcinomas in situ, and 11 carcinomas of other specific subtypes. Other clinicopathological characteristics of the 123 cases of breast cancer are summarized in Table 2.

Of the 13 cases whose FFPE nipple tissues were tested for $\mathrm{HPV}$, one case was positive for HPV-16 infection in uterine cervix and 12 cases were positive for HPV infection in uterine cervix by Hybrid Capture 2 (Qiagen, Gaithersburg, MD, USA) (Table 3). Of these 13 cases, five had low-grade squamous intraepithelial lesions, one had high-grade squamous intraepithelial lesion, and one had endocervical type adenocarcinoma in uterine cervix.

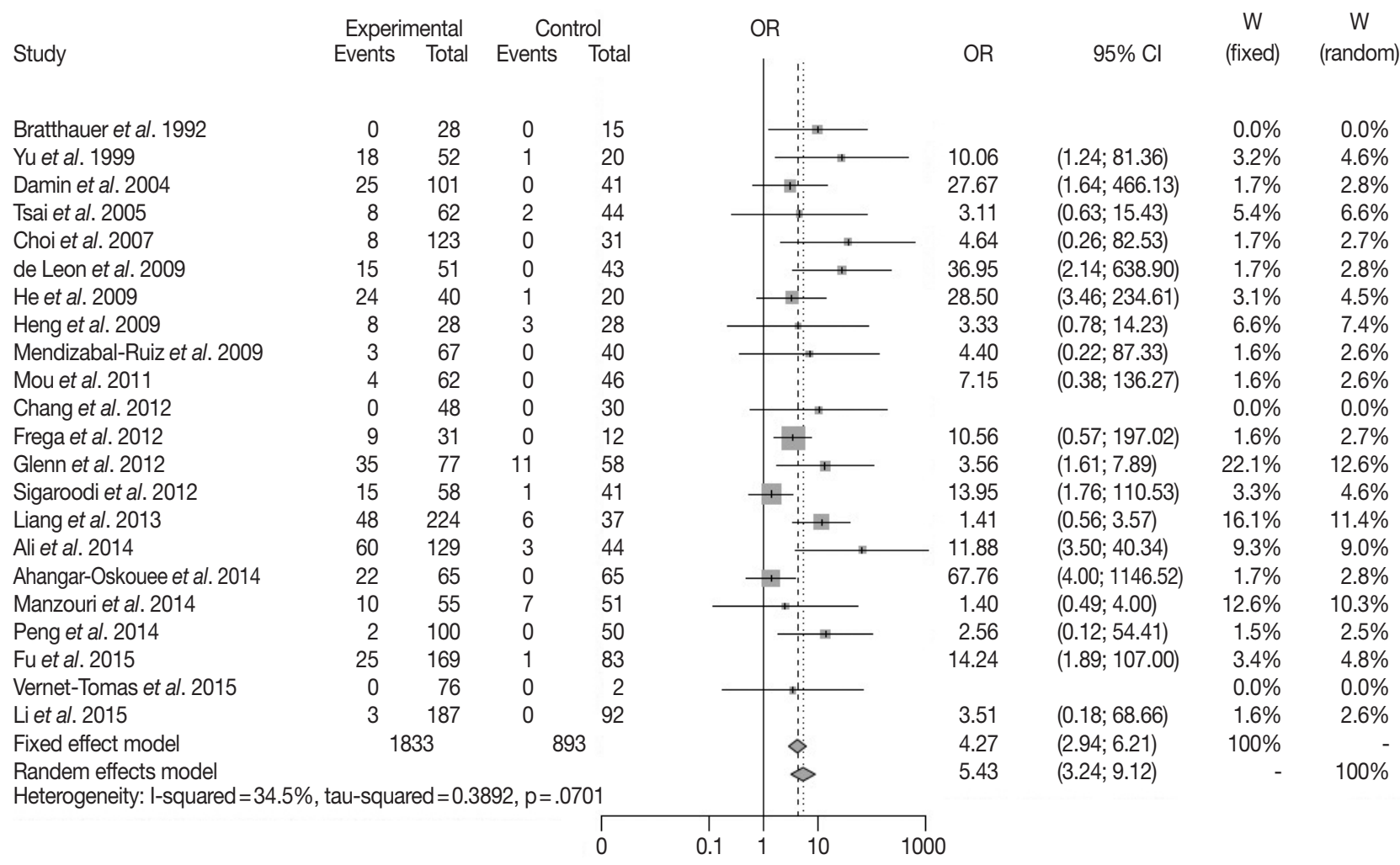

Fig. 1. The forest plot for relationship between breast cancer and human papillomavirus infection in case-control setting. $5,7-9,11-19,23-26,28,33-36$ $\mathrm{OR}$, odds ratio; $\mathrm{Cl}$, confidence interval. 
Availability of Anyplex II HPV 28 Detection System in FFPE tissue

HPV-16 was detected in the FFPE tissue of uterine cervical

Table 2. Clinicopathological characteristics of 123 cases of breast cancer

\begin{tabular}{|c|c|c|}
\hline Characteristic & Criteria & No. \\
\hline \multirow[t]{3}{*}{ Age } & $34-50$ & 67 \\
\hline & $51-66$ & 56 \\
\hline & Median (range) & $\begin{array}{c}51.6 \\
(23-79)\end{array}$ \\
\hline \multirow[t]{2}{*}{ Operation type } & Mastectomy & 108 \\
\hline & Conserving operation & 15 \\
\hline \multirow[t]{3}{*}{ Histologic grade } & Grade 1 & 27 \\
\hline & Grade 2 & 41 \\
\hline & Grade 3 & 52 \\
\hline \multirow[t]{4}{*}{ Hormonal receptor } & ER positive & 69 \\
\hline & PR positive & 62 \\
\hline & HER2 positive & 52 \\
\hline & Triple negative & 25 \\
\hline \multirow{2}{*}{$\begin{array}{l}\text { Lymph node } \\
\text { metastasis }\end{array}$} & Positive & 54 \\
\hline & Negative & 69 \\
\hline \multirow{2}{*}{$\begin{array}{l}\text { HPV detection } \\
\text { in cervix }\end{array}$} & Positive & 54 \\
\hline & Negative & 69 \\
\hline \multirow[t]{11}{*}{ Histologic type } & Invasive carcinoma of no special type & 103 \\
\hline & Invasive lobular carcinoma & 5 \\
\hline & Microinvasive carcinoma & 1 \\
\hline & Ductal carcinoma in situ & 3 \\
\hline & Metaplastic carcinoma & 2 \\
\hline & Carcinoma with medullary feature & 2 \\
\hline & Apocrine carcinoma & 2 \\
\hline & Carcinoma with neuroendocrine feature & 1 \\
\hline & Adenoid cystic carcinoma & 1 \\
\hline & Mucinous carcinoma & 1 \\
\hline & Micropapillary carcinoma & 1 \\
\hline
\end{tabular}

ER, estrogen receptor; PR, progesterone receptor; HER2, human epidermal growth factor receptor 2; HPV, human papillomavirus. squamous cell carcinoma using Anyplex II HPV 28 Detection System, in concordance with the result of cytology sample using Anyplex II HPV 28 Detection System, proving that Anyplex II HPV 28 Detection System worked properly for FFPE tissue as for the cytology specimen. Therefore, Anyplex II HPV 28 Detection System can be used to detect HPV infection in FFPE tissue.

\section{Real-time PCR}

Proper DNA samples were isolated from 106 FFPE breast cancers, 17 touch imprint cytology samples of breast cancer, 13 FFPE nipple tissues, and nine FFPE intraductal papillomas. Amplification of dissociation curve of HPV subtypes 6, 16, 33, $39,40,51,53,58$, and 61 was detected in real-time PCR of 22 FFPE breast cancers (17.9\%) (Fig. 2). The 22 cases included 19 cases of invasive carcinoma of no special type, one case of adenoid cystic carcinoma, one case of metaplastic carcinoma, and one case of apocrine carcinoma (Table 4). Histological features of HPV infection were not identified by slide review of these 22 cases. In two FFPE tissues of intraductal papilloma, amplification of dissociation curve of HPV- 33 and HPV-53 was detected in real-time PCR (22.2\% of nine intraductal papilloma FFPE tissues). However, because HPV-positive cases showed weak amplification of the dissociation curve, these results were considered as weak positivity for HPV. HPV was not detected in 17 touch imprint cytology samples of breast cancer or 13 FFPE tissues of nipple.

\section{DISCUSSION}

Genetic and environmental factors such as mutation in $B R C A 1 / 2$, ethnicity, hormonal effect, diet, and ionizing radiation are known to be involved in the carcinogenesis of breast cancer.

Table 3. Clinicopathologic data of breast cancer patients confirmed HPV infection in uterine cervix

\begin{tabular}{|c|c|c|c|c|c|}
\hline Case No. & $\begin{array}{l}\text { Age of breast } \\
\text { surgery (yr) }\end{array}$ & Histology of breast & $\begin{array}{l}\text { Age of HPV detection } \\
\text { at uterine cervix (yr) }\end{array}$ & Histology of uterine cervix & Method \\
\hline 15 & 50 & Invasive carcinoma of NST & 54 & $\mathrm{NI}$ & $\mathrm{HC} 2$ \\
\hline 16 & 44 & Metaplastic carcinoma & 44 & LSIL & $\mathrm{HC} 2$ \\
\hline 17 & 43 & Invasive carcinoma of NST & 44 & LSIL & $\mathrm{HC} 2$ \\
\hline 18 & 48 & Invasive carcinoma of NST & 48 & $\mathrm{NI}$ & $\mathrm{HC} 2$ \\
\hline 19 & 50 & Invasive carcinoma of NST & 50 & $\mathrm{NI}$ & $\mathrm{HC} 2$ \\
\hline 20 & 46 & Invasive carcinoma of NST & 46 & LSIL & $\mathrm{HC} 2$ \\
\hline 21 & 43 & Invasive carcinoma of NST & 41 & $\mathrm{Nl}$ & $\mathrm{HC} 2$ \\
\hline 22 & 49 & Invasive carcinoma of NST & 49 & $\mathrm{NI}$ & $\mathrm{HC} 2$ \\
\hline 23 & 44 & Invasive carcinoma of NST & 44 & LSIL & $\mathrm{HC} 2$ \\
\hline 24 & 63 & Invasive carcinoma of NST & 60 & Adenocarcinoma, endocervical type & $\mathrm{HC} 2$ \\
\hline 25 & 50 & Invasive carcinoma of NST & 50 & $\mathrm{Nl}$ & Medical record (HPV-16) \\
\hline 38 & 56 & Invasive carcinoma of NST & 47 & LSIL & $\mathrm{HC} 2$ \\
\hline 56 & 57 & Invasive carcinoma of NST & 46 & HSIL & $\mathrm{HC} 2$ \\
\hline
\end{tabular}

HPV, human papillomavirus; NST, no special type; NI, in the biopsy, uterine cenvical lesion was not identified; HC2, Hybrid Capture 2 (QIAGEN, Gaithersburg, MD, USA) in cytology sample; LSIL, low-grade squamous intraepithelial lesions; HSIL, high-grade squamous intraepithelial lesions. 
However, two-thirds of patients with breast cancer have no association with these risk factors. ${ }^{37}$ To elucidate viral carcinogenesis in mammary cancer development, many studies have focused on oncogenic virus. According to multistep carcinogenesis model of breast cancer, TP53 is considered as one predisposing gene. Because HPV E6 and E7 oncoproteins are able to inactivate TP53 gene,
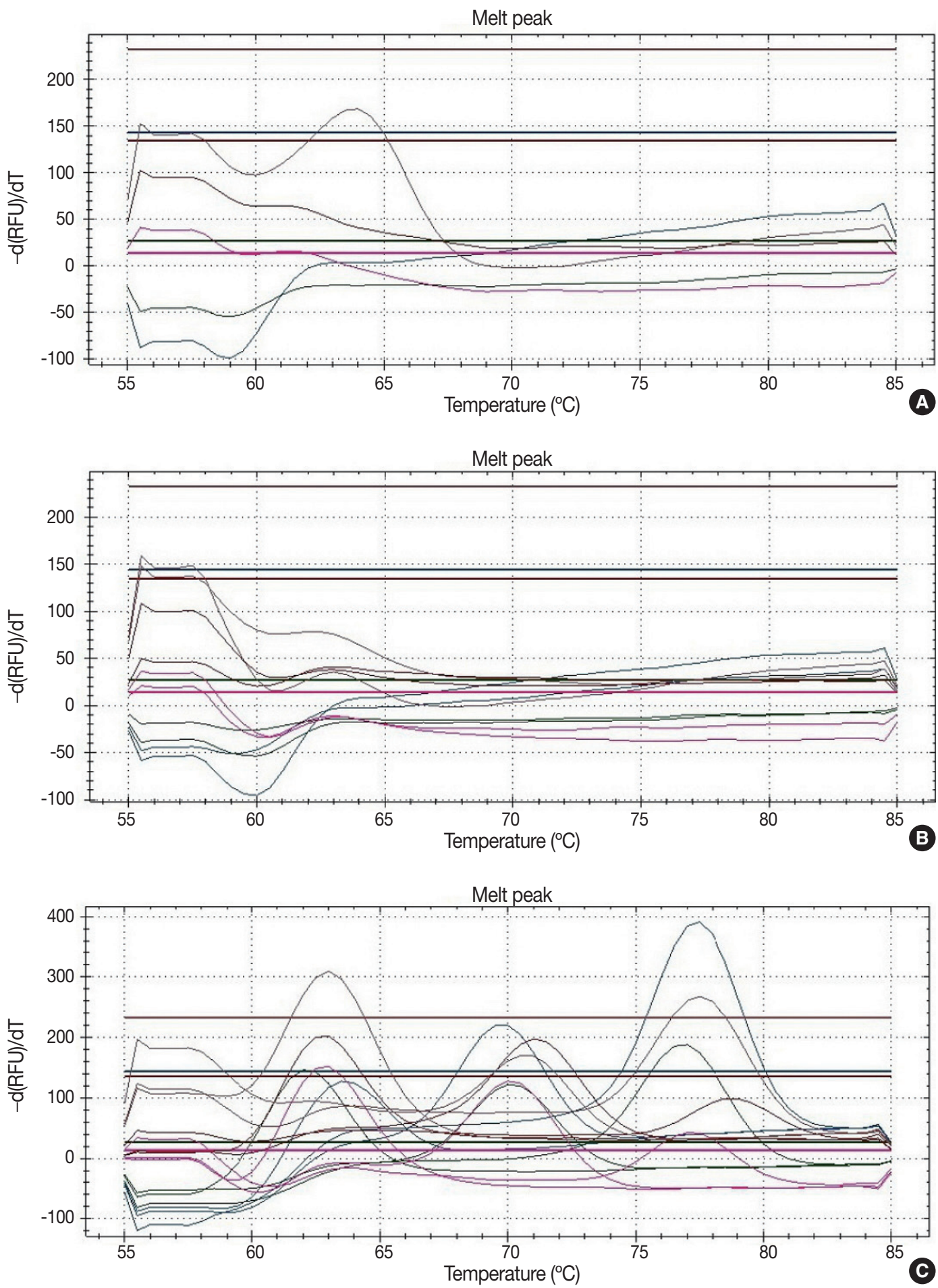

Fig. 2. The representative results of dissociation curve in real-time polymerase chain reaction. (A) Weak positivity for human papillomavirus (HPV) 33. The dissociation curve of two cases shows the low melting peak. (B) Negative case. The dissociation curve of almost cases do not show the melting peaks. (C) Positive control. The dissociation curve of positive control shows 28 melting peaks about 28 subtypes of HPV.

(Continued to the next page) 


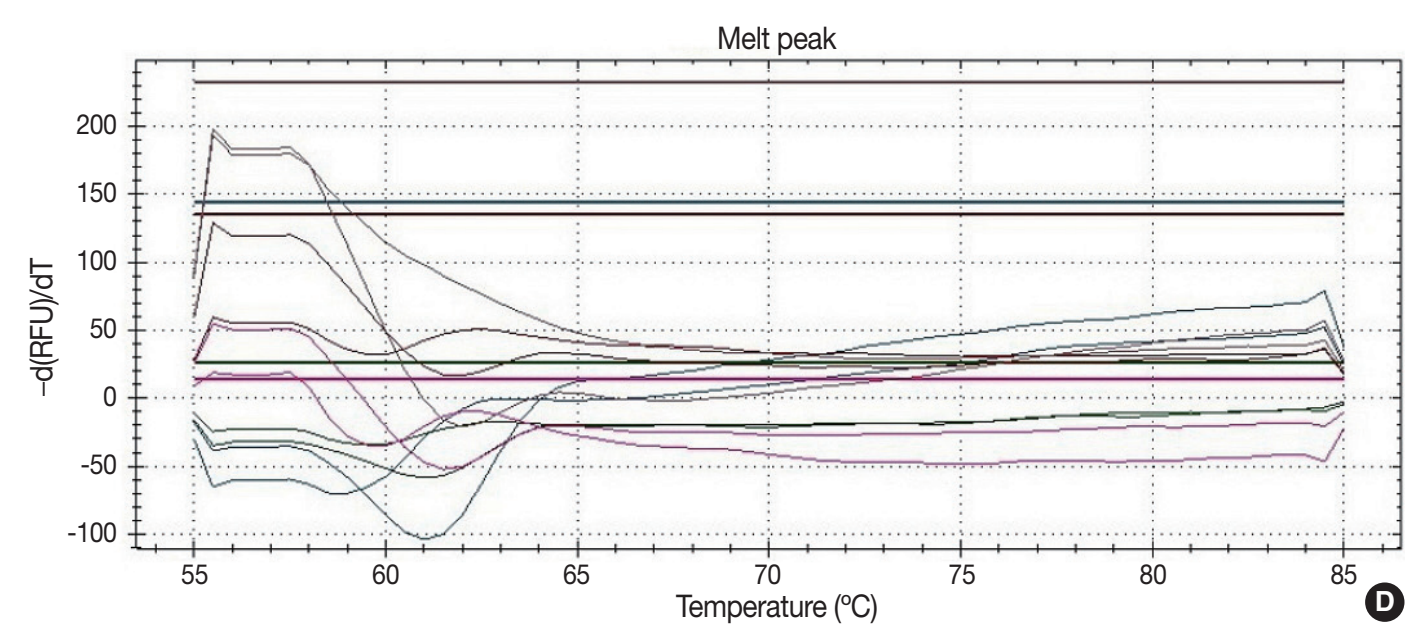

Fig. 2. (Continued from the previous page) (D) Negative control.

Table 4. Clinicopathologic data and HPV subtype of HPV-positive breast cancer

\begin{tabular}{|c|c|c|c|c|}
\hline Case No. & Age (yr) & Sample & Histologic type & HPV subtype \\
\hline 1 & 50 & FFPE & Invasive carcinoma of NST & 33 \\
\hline 3 & 46 & FFPE & Invasive carcinoma of NST & 33 \\
\hline 8 & 55 & FFPE & Adenoid cystic carcinoma & $40,51,61$ \\
\hline 9 & 63 & FFPE & Metaplastic carcinoma & $40,51,53,61$ \\
\hline 17 & 23 & FFPE & Invasive carcinoma of NST & $40,51,53,61$ \\
\hline 20 & 32 & FFPE & Invasive carcinoma of NST & 51,53 \\
\hline 30 & 47 & FFPE & Invasive carcinoma of NST & $40,51,58$ \\
\hline 39 & 44 & FFPE & Invasive carcinoma of NST & 51 \\
\hline 40 & 40 & FFPE & Invasive carcinoma of NST & $33,51,53$ \\
\hline 41 & 49 & FFPE & Invasive carcinoma of NST & 51,53 \\
\hline 49 & 55 & FFPE & Invasive carcinoma of NST & 51 \\
\hline 50 & 38 & FFPE & Invasive carcinoma of NST & 51 \\
\hline 63 & 70 & FFPE & Invasive carcinoma of NST & $6,51,58$ \\
\hline 73 & 42 & FFPE & Invasive carcinoma of NST & $6,40,53$ \\
\hline 74 & 58 & FFPE & Invasive carcinoma of NST & 6,51 \\
\hline 75 & 54 & FFPE & Invasive carcinoma of NST & 51 \\
\hline 81 & 65 & FFPE & Invasive carcinoma of NST & 6,40 \\
\hline 93 & 35 & FFPE & Invasive carcinoma of NST & 53 \\
\hline 99 & 54 & FFPE & Invasive carcinoma of NST & 6 \\
\hline 109 & 50 & FFPE & Invasive carcinoma of NST & 51 \\
\hline 120 & 63 & FFPE & Apocrine carcinoma & 16 \\
\hline 122 & 50 & FFPE & Invasive carcinoma of NST & 39 \\
\hline
\end{tabular}

HPV, human papillomavirus; FFPE, formalin-fixed and paraffin embedded tissue; NST, no special type.

HPV can play a role in this multistep mammary carcinogenesis. On the other hand, Ohba et al. ${ }^{38}$ have suggested that HPV infection induces overexpression of $\mathrm{APOBEC} 3 \mathrm{~B}$ associated with the early stage of carcinogenesis in breast cancer.

Recently, many studies have been performed to prove the relationship between breast cancer and HPV infection. These studies have revealed that approximately $19.8 \%$ of HPV infections are in breast cancer (range, $0 \%$ to $60 \%$ ). The causes of no detection of HPV infection include geographic factors due to race and prevalence of HPV infection, selection bias due to difference in prevalence, and too low viral load to be technically detectable. At present, most studies performed in China and Middle East have showed high prevalence of positivity for HPV in breast cancer.

Meta-analysis from case-control setting revealed that the prevalence of HPV infection in breast cancer was higher than that in benign breast lesion. The $\mathrm{I}^{2}$ was appropriate for random effect model. The overall odds ratio between breast cancer and HPV infection was statistically significant. However, there are some limitations of meta-analysis. First, publication bias might 
exist due to low prevalence of HPV infection in breast cancers. Many studies that failed to detect HPV in breast cancer might not have been reported in the literature. Moreover, because 22 studies were performed with different methods that could only detect limited HPV subtypes, the prevalence of HPV infection in breast cancer might have been underestimated. Therefore, the quality of data from the literature might be questionable.

We found that variable HPV subtypes were detected in 22 of 123 Korean breast cancers by real-time PCR. Specific HPV subtypes including HPV-39, HPV-40, HPV-53, and HPV-61 have not been mentioned in the literature. HPV-51 was the most frequently found subtype. It was detected in 14 of $22 \mathrm{HPV}$ positive breast cancers. HPV-16 and HPV-18 were the most frequently found subtypes in cervical cancer and oropharyngeal cancer. However, they were not common HPV subtypes in breast cancer. They were not detected in the two intraductal papillomas either. If HPV infection is involved in carcinogenesis of breast, specific HPV subtypes hardly related in cervical cancer and oropharyngeal cancer can have a role as carcinogen in breast. Interestingly, this result showed that the prevalence of HPV infection in benign breast lesions (22.2\%) was higher than that in breast cancers (17.9\%), although meta-analysis supported correlation between breast cancer and HPV. However, because only nine intraductal papillomas were tested, this result might have been compromised.

It is important to note that most cases showed weak positivity for HPV. Fragmentation of extracted DNA in FFPE tissues could be one of the reasons responsible for this result. However, even when the reduction of positivity by fragmentation was considered, positivity for HPV in FFPE breast cancer samples was too weak. Khan et al. ${ }^{39}$ have also found HPV DNA in 26 of 124 Japanese breast cancer patients by PCR for FFPE breast cancer samples. Because the viral load in breast cancers was very low compared to viral load examined in uterine cervical carcinoma, they concluded that HPV was not involved in the development of breast cancers in Japanese. Due to the weak positivity of HPV in this study, we also concluded that this result was not a significant evidence to support carcinogenesis of HPV in breast.

If HPV is involved in the development of breast cancer, some differences between HPV-positive and HPV-negative breast cancers should be present. Heng et al. ${ }^{13}$ have found putative koilocytes as the proof of HPV infection in HPV-positive breast cancers. However, Khan et al. ${ }^{39}$ reviewed all HPV-positive breast cancer and failed to find koilocytes. In this study, we also failed to find koilocytes after slide review of the 123 breast cancers and nine intraductal papillamas. Kan $e t ~ a l .^{40}$ have reported that
HPV-positive breast cancers are not correlated with grade, patient survival, hormonal receptor status, HER-2 expression, or p53 overexpression. The characteristics of HPV-positive breast cancer are still controversial.

Since HPV is known as a sexually transmitted virus, HPV may be transmitted to the breast tissue through nipple by sexual behavior. We didn't detect HPV infection in 13 nipple FFPE tissues and FFPE breast cancers of patients who had HPV infection in uterine cervix (Table 3) and failed prove that nipple was the infection route. However, Glenn et al. ${ }^{17}$ have suggested that HPV can be detected in the epithelial cells extracted from human milk. In addition, de Villiers et al. ${ }^{41}$ have detected HPV infection in nipple tissues. Some studies have tried to prove the coexistence of HPV infection in both cervical lesion and breast cancer. Hennig et $a l^{6}$ have proved that HPV-16 positive breast cancer is corresponding to HPV-16 positive high-grade cervical intraepithelial neoplasia in 19 of 41 cases. On the contrary, Lv et al. ${ }^{42}$ failed to find coexistence of HPV in breast or cervical tissues of 12 cases. In our study, there was no case of HPV coexistence in cervical lesion or breast cancer. Furthermore, although most cervical and oropharyngeal cancers are provoked by HPV-16 and HPV-18, and HPV-16 was found in one breast cancer only. Common infected HPV subtypes of breast cancer might be different from those of cervical and oropharyngeal cancers. It is not convincing that the cervical intraepithelial neoplasia is one of the risk factors of breast cancer.

Statistical significance of correlation between breast cancer and HPV was found in meta-analysis using published studies of casecontrol setting. In addition, we detected $22 \mathrm{HPV}$-positive breast cancers in 123 Korean patients and two HPV-positive intraductal papillomas in nine Korean patients without finding histological characteristics of HPV infection in breast cancers. Because all HPV-positive breast cancers showed weak positivity, a correlation between HPV and breast cancer was not confirmed in this study. Further study with larger epidemiologic population is necessary to elucidate the role of HPV in mammary carcinogenesis.

\section{Conflicts of Interest}

No potential conflict of interest relevant to this article was reported.

\section{REFERENCES}

1. Cobos C, Figueroa JA, Mirandola L, et al. The role of human papilloma virus (HPV) infection in non-anogenital cancer and the prom- 
ise of immunotherapy: a review. Int Rev Immunol 2014; 33: 383-401.

2. Wang $\mathrm{T}$, Chang $\mathrm{P}$, Wang $\mathrm{L}$, et al. The role of human papillomavirus infection in breast cancer. Med Oncol 2012; 29: 48-55.

3. Lewis A, Kang R, Levine A, Maghami E. The new face of head and neck cancer: the HPV epidemic. Oncology (Williston Park) 2015; 29: 616-26.

4. Alibek K, Kakpenova A, Mussabekova A, Sypabekova M, Karatayeva N. Role of viruses in the development of breast cancer. Infect Agent Cancer 2013; 8: 32.

5. Yu Y, Morimoto T, Sasa M, et al. HPV33 DNA in premalignant and malignant breast lesions in Chinese and Japanese populations. Anticancer Res 1999; 19: 5057-61.

6. Hennig EM, Suo Z, Thoresen S, Holm R, Kvinnsland S, Nesland JM. Human papillomavirus 16 in breast cancer of women treated for high grade cervical intraepithelial neoplasia (CIN III). Breast Cancer Res Treat 1999; 53: 121-35.

7. Damin AP, Karam R, Zettler CG, Caleffi M, Alexandre CO. Evidence for an association of human papillomavirus and breast carcinomas. Breast Cancer Res Treat 2004; 84: 131-7.

8. Tsai JH, Tsai CH, Cheng MH, Lin SJ, Xu FL, Yang CC. Association of viral factors with non-familial breast cancer in Taiwan by comparison with non-cancerous, fibroadenoma, and thyroid tumor tissues. J Med Virol 2005; 75: 276-81.

9. Choi YL, Cho EY, Kim JH, et al. Detection of human papillomavirus DNA by DNA chip in breast carcinomas of Korean women. Tumour Biol 2007; 28: 327-32.

10. Akil N, Yasmeen A, Kassab A, Ghabreau L, Darnel AD, Al Moustafa AE. High-risk human papillomavirus infections in breast cancer in Syrian women and their association with Id-1 expression: a tissue microarray study. Br J Cancer 2008; 99: 404-7.

11. de Leon DC, Montiel DP, Nemcova J, et al. Human papillomavirus (HPV) in breast tumors: prevalence in a group of Mexican patients. BMC Cancer 2009; 9: 26.

12. He Q, Zhang SQ, Chu YL, Jia XL, Wang XL. The correlations between HPV16 infection and expressions of c-erbB-2 and bcl-2 in breast carcinoma. Mol Biol Rep 2009; 36: 807-12.

13. Heng B, Glenn WK, Ye Y, et al. Human papilloma virus is associated with breast cancer. Br J Cancer 2009; 101: 1345-50.

14. Mendizabal-Ruiz AP, Morales JA, Ramirez-Jirano LJ, Padilla-Rosas M, Moran-Moguel MC, Montoya-Fuentes H. Low frequency of human papillomavirus DNA in breast cancer tissue. Breast Cancer Res Treat 2009; 114: 189-94.

15. Mou X, Chen L, Liu F, et al. Low prevalence of human papillomavirus (HPV) in Chinese patients with breast cancer. J Int Med Res 2011; 39: 1636-44.

16. Frega A, Lorenzon L, Bononi M, et al. Evaluation of E6 and E7
mRNA expression in HPV DNA positive breast cancer. Eur J Gynaecol Oncol 2012; 33: 164-7.

17. Glenn WK, Heng B, Delprado W, Iacopetta B, Whitaker NJ, Lawson JS. Epstein-Barr virus, human papillomavirus and mouse mammary tumour virus as multiple viruses in breast cancer. PLoS One 2012; 7: e48788.

18. Sigaroodi A, Nadji SA, Naghshvar F, Nategh R, Emami H, Velayati AA. Human papillomavirus is associated with breast cancer in the north part of Iran. ScientificWorldJournal 2012; 2012: 837191.

19. Liang W, Wang J, Wang C, et al. Detection of high-risk human papillomaviruses in fresh breast cancer samples using the hybrid capture 2 assay. J Med Virol 2013; 85: 2087-92.

20. Pereira Suarez AL, Lorenzetti MA, Gonzalez Lucano R, et al. Presence of human papilloma virus in a series of breast carcinoma from Argentina. PLoS One 2013; 8: e61613.

21. Herrera-Goepfert R, Vela-Chavez T, Carrillo-Garcia A, et al. Highrisk human papillomavirus (HPV) DNA sequences in metaplastic breast carcinomas of Mexican women. BMC Cancer 2013; 13: 445.

22. Francis IM, Al-Ayadhy B, Al-Awadhi S, Kapila K, Al-Mulla F. Prevalence and correlation of human papilloma virus and its types with prognostic markers in patients with invasive ductal carcinoma of the breast in kuwait. Sultan Qaboos Univ Med J 2013; 13: 527-33.

23. Ali SH, Al-Alwan NA, Al-Alwany SH. Detection and genotyping of human papillomavirus in breast cancer tissues from Iraqi patients. East Mediterr Health J 2014; 20: 372-7.

24. Ahangar-Oskouee M, Shahmahmoodi S, Jalilvand S, et al. No detection of 'high-risk' human papillomaviruses in a group of Iranian women with breast cancer. Asian Pac J Cancer Prev 2014; 15: 4061-5.

25. Manzouri L, Salehi R, Shariatpanahi S, Rezaie P. Prevalence of human papilloma virus among women with breast cancer since 20052009 in Isfahan. Adv Biomed Res 2014; 3: 75.

26. Peng J, Wang T, Zhu $\mathrm{H}$, et al. Multiplex PCR/mass spectrometry screening of biological carcinogenic agents in human mammary tumors. J Clin Virol 2014; 61: 255-9.

27. Piana AF, Sotgiu G, Muroni MR, Cossu-Rocca P, Castiglia P, De Miglio MR. HPV infection and triple-negative breast cancers: an Italian case-control study. Virol J 2014; 11: 190.

28. Li J, Ding J, Zhai K. Detection of human papillomavirus DNA in patients with breast tumor in China. PLoS One 2015; 10: e0136050.

29. Fernandes A, Bianchi G, Feltri AP, Perez M, Correnti M. Presence of human papillomavirus in breast cancer and its association with prognostic factors. Ecancermedicalscience 2015; 9: 548.

30. Lindel K, Forster A, Altermatt HJ, Greiner R, Gruber G. Breast cancer and human papillomavirus (HPV) infection: no evidence of a viral etiology in a group of Swiss women. Breast 2007; 16: $172-7$.

31. Hedau S, Kumar U, Hussain S, et al. Breast cancer and human pap- 
illomavirus infection: no evidence of HPV etiology of breast cancer in Indian women. BMC Cancer 2011; 11: 27.

32. Kwong A, Leung CP, Shin VY, Ng EK. No evidence of human papillomavirus in patients with breast cancer in Hong Kong, Southern China. ISRN Virol 2013;2013:546503.

33. Vernet-Tomas M, Mena M, Alemany L, et al. Human papillomavirus and breast cancer: no evidence of association in a Spanish set of cases. Anticancer Res 2015; 35: 851-6.

34. Bratthauer GL, Tavassoli FA, O'Leary TJ. Etiology of breast carcinoma: no apparent role for papillomavirus types 6/11/16/18. Pathol Res Pract 1992; 188: 384-6.

35. Chang P, Wang T, Yao Q, et al. Absence of human papillomavirus in patients with breast cancer in north-west China. Med Oncol 2012; 29: 521-5.

36. Fu L, Wang D, Shah W, Wang Y, Zhang G, He J. Association of human papillomavirus type 58 with breast cancer in Shaanxi province of China. J Med Virol 2015; 87: 1034-40.

37. Beckmann MW, Niederacher D, Schnurch HG, Gusterson BA, Bender HG. Multistep carcinogenesis of breast cancer and tumour heterogeneity. J Mol Med (Berl) 1997; 75: 429-39.

38. Ohba K, Ichiyama K, Yajima M, et al. In vivo and in vitro studies suggest a possible involvement of HPV infection in the early stage of breast carcinogenesis via APOBEC3B induction. PLoS One 2014; 9: e97787.

39. Khan NA, Castillo A, Koriyama C, et al. Human papillomavirus detected in female breast carcinomas in Japan. Br J Cancer 2008; 99 : 408-14.

40. Kan CY, Iacopetta BJ, Lawson JS, Whitaker NJ. Identification of human papillomavirus DNA gene sequences in human breast cancer. Br J Cancer 2005; 93: 946-8.

41. de Villiers EM, Sandstrom RE, zur Hausen H, Buck CE. Presence of papillomavirus sequences in condylomatous lesions of the mamillae and in invasive carcinoma of the breast. Breast Cancer Res 2005; 7: R1-11.

42. Lv YR, Wang JL, Zhang K, et al. Human papilloma viruses (HPVs) no co-existence in breast cancer and cervical cells in the same patient. Chin J Physiol 2014; 57: 105-6. 